\title{
Marcadores tumorais específicos para câncer de ovário CA 125: revisão integrativa
}

\author{
Tumor markers specific to ovary cancer CA 125: integrative review
}

Marcadores de tumor específicos del cáncer de ovario CA 125: revisión integradora

Natasha de Souza Pontes ${ }^{1 *}$, Carolina Pontes Soares ${ }^{2}$.

\section{RESUMO}

Objetivo: Descrever sobre o papel do marcador tumoral CA 125 mediante o diagnóstico de carcinoma de ovário. Métodos: Este estudo é uma revisão integrativa, na qual foram realizados levantamentos bibliográficos e análises de aproximadamente 15 artigos em periódicos científicos encontrados nas bases de dados: MEDLINE, LILACS, SCIELO, BIREME e PubMed, no período de 2011 a 2021. Nesta revisão foram incluídos estudos que se concentraram em abordar os tipos de marcadores tumorais (evidenciando CA 125 e MUC 16). Resultados: A neoplasia epitelial maligna do ovário é evidente entre os tipos de tumores de malignidade agressiva que acometem o aparelho reprodutor feminino, por se tratar de uma doença de difícil controle. Dessa forma, a sobrevida desses pacientes está bem abaixo das demais, sendo de suma importância o diagnóstico precoce. O biomarcador CA125 foi considerado como tendo um alto nível de sensibilidade. Considerações Finais: O biomarcador sérico CA125 é incapaz de confirmar diagnóstico sozinho, pois se altera com outras doença benignas, porém é muito utilizado na prática clínica para auxilio no diagnostico de câncer de ovário.

Palavras-chave: Carcinoma de ovário, Marcadores de tumor, Antígeno CA 125.

\begin{abstract}
Objective: Describe about the tumor marker CA 125 in the diagnosis of ovarian carcinoma. Methods: This study is integrative review, in which bibliographical surveys and analyzes of about 15 articles and scientific journals found in the databases: MEDLINE, LILACS, SCIELO, BIREME and PubMed, from 2005 to 2021 were carried out. In this review were included studies that focused on addressing the types of tumor markers (evidencing CA 125 and MUC 16). Results: Ovarian malignant epithelial neoplasia is evident among the types of tumors with aggressive malignancy that affect the female reproductive tract, as it is a disease that is difficult to control. Thus, the survival of these patients is well below the others, early diagnosis is of utmost importance. The CA125 biomarker was considered to have a high level of sensitivity. Final considerations: The CA125 biomarker serum it is unable to confirm the diagnosis alone, as it changes with other benign diseases, but it is widely used in clinical practice to aid in the diagnosis of ovarian cancer.
\end{abstract}

Key words: Ovarian carcinoma, Markers tumor, CA 125 antigen.

\section{RESUMEN}

Objetivo: Describir sobre el marcador tumoral CA 125 todavia en el en el diagnóstico del cáncer de ovario. Métodos: Este estudio es una revisión integrador, donde se realizaron levantamiento bibliográficas y análisis acerta de 15 artículos en revistas científicas que se encuentran en las bases de datos: MEDLINE, LILACS, SCIELO, BIREME e PubMed,en el periodo de 2005 a 2021.En este trabajo se incluyeron temas que

${ }^{1}$ Centro Universitário do Norte (UNINORTE), Rio Branco - Acre. *E-mail: natashapontes.rbac@gmail.com

2 Universidade Federal do Acre UFAC, Rio Branco - Acre. 
priorizaron el abordaje de los tipos de marcadores tumorales (evidenciando CA 125 y MUC 16). Resultados: La neoplasia epitelial maligna de ovario es evidente entre tipos de tumores malignos agresivo que afectan el órgano reproductor femenino, por tener difícil control. De esta forma, la supervivencia de estos pacientes están muy por debajo delos demás, el diagnóstico precoz es de suma importancia. Se consideró que el biomarcador CA125 tenía un alto nivel de sensibilidad. Consideraciones finales: El biomarcador sérico CA125 no puede confirmar el diagnóstico por sí solo, ya que cambia con otras enfermedades benignas, pero se usa ampliamente en la práctica clínica para ayudar en el diagnóstico del cáncer de ovario.

Palabras-clave: Carcinoma de ovario, Marcadores tumor, Antígeno CA 125.

\section{INTRODUÇÃO}

O câncer ovariano ou neoplasia maligna epitelial de ovário, encontra-se no topo da lista dos cânceres com maior frequência do trato genital feminino. O câncer de ovário atingiu a sétima posição no ranking mundial dos canceres mais comuns, dentre os casos registrados cerca de 5 á 10\% desenvolvem para metástase, ou seja, é de suma importância que quando diagnosticado haja uma intervenção rápida e tratamento adequado, a fim de evitar tal agravo. Este processo ocorre devido a várias e consecutivas mutações dos genes específicos do ovário o BRCA1 e BRCA2, cada tipo de câncer é proveniente de mutações gênicas distintas de acordo com o órgão acometido. O câncer ovariano se encaixa na segunda neoplasia ginecológica mais comum, em primeiro está o câncer do colo do útero (RIEDINGER JM,et al., 2006).

De acordo com Instituto Nacional do Câncer (INCA) as neoplasias ovarianas, sendo 95\% são provenientes das células epiteliais, responsáveis pelo revestimento do ovário, os outros $5 \%$ são oriundas de células germinativas (responsável pela formação dos óvulos) e células estromais (responsável pela produção de grande parte dos hormônios femininos). Com um prognóstico ruim, pelo fato da maioria dos casos serem descobertos em um estágio avançado no qual a maioria são incuráveis, estima-se para estes pacientes uma sobrevida de aproximadamente cinco anos em $40 \%$ dos casos registrados (INCA, 2021).

As funções dos marcadores biológicos são de identificação das alterações que surgem nas células, descobertas através de longas pesquisas na parte do âmbito biológico, bioquímico e imunológico molecular, começaram a ser estudados para a sua utilização no diagnóstico pré-operatório dos tumores (SZUBERT M, et al., 2012). Os cânceres agressivos são geralmente mais profundos, assim dificultando sua identificação, nesse caso os exames usuais não conseguem detectar e os marcadores são propostos com o intuito de diagnóstico efetivo para todos os tipo de cânceres (ZOMER MT, et al., 2013). A PORTARIA SCTIE/MS № 37, de setembro de 2012 torna pública a decisão de incorporar a dosagem do antígeno CA 125 para acompanhamento do tratamento e seguimento pós-tratamento de neoplasia maligna epitelial de ovário no Sistema Único de Saúde no Brasil (BRASIL, 2012).

Este estudo possui o objetivo de esclarecer se o biomarcador CA 125 realmente é utilizado na prática clínica e se tem efetividade no auxilio do diagnostico, mesmo com o passar dos anos e avanço da tecnologia em relação a descobertas de novos marcadores.

\section{MÉTODOS}

Esse estudo é uma revisão interativa realizado através de estados encontrado em 60 artigos e revistas cientificas encontrados nas linguagens português, espanhol e inglês, achados em navegadores online grátis, foram utilizadas as bases de dados: Literatura Internacional em Ciências da Saúde (MEDLINE), Literatura Latino americana em Ciência da Saúde (LILACS), Scientific Electronic Library Online (SCIELO), Cochrane Collaboration, Biblioteca Regional de Medicina (BIREME) e National Library of Medicine and National Institute of Health (PUBMED) do ano de 2005 á 2021.

Os trabalhos que participaram dos critérios de inclusão são os que continham assuntos que priorizavam a abordagem dos marcadores tumorais específicos CA125 E MUC16, câncer de ovário e tumores identificados no trato genital feminino. Os demais trabalhos que não continha as informações necessárias entraram para 
os critérios de exclusão, como os que abordavam leucemias, doenças associadas a cânceres, artigos que utilizaram dados de somente uma cidade do Brasil e trabalhos publicados do ano de 2004 e anteriores a este.

Na Figura 1, temos um fluxograma que detém os temas pesquisados e a quantidade de trabalhos que foram encontrados de acordo com o proposto, percebe-se que de acordo com o acréscimo de informações na pesquisa do tema tínhamos uma diminuição notável na quantidade de trabalhos publicados.

Figura 1 - Fluxograma do processo de construção desta revisão.

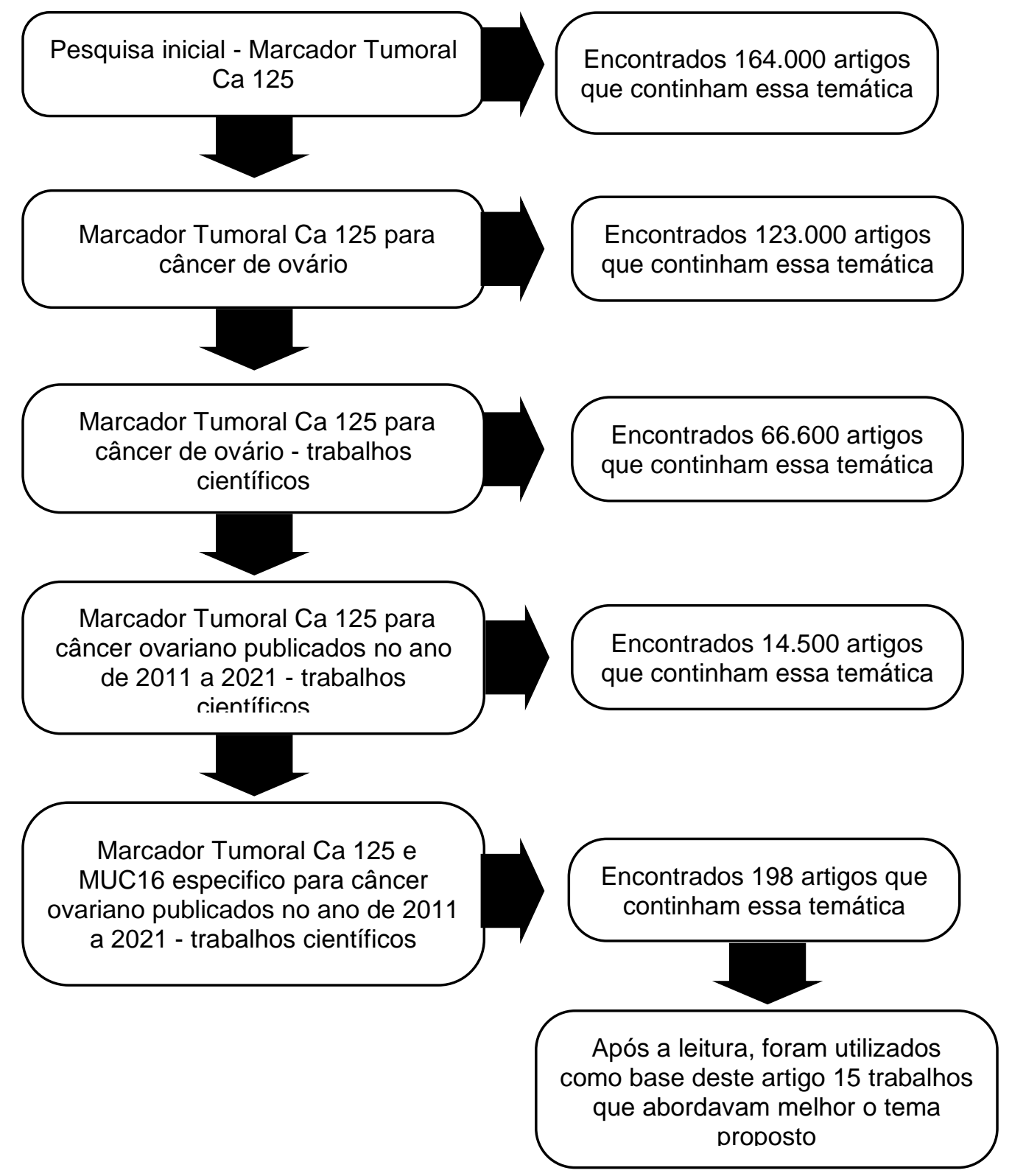

Fonte: Pontes NS e Soares CP, 2021.

\section{RESULTADOS E DISCUSSÃO}

Os marcadores tumorais são fragmentos de proteínas ou proteínas grandes (macromoléculas), que fazem parte da composição tumoral, é encontrada em líquidos biológicos como sangue e soro, os marcadores abrangem enzimas, proteínas citoplasmáticas, hormônios e antígenos de superfície de células. Estão diretamente ligados a proliferação e desenvolvimento de células neoplásicas, assim auxiliando no diagnostico, pois são fabricadas tanto pelo organismo quanto pelas células tumorais. Os indicadores são super 
importantes no manejo clinico de pessoas portadoras de câncer, sendo ideal se lograsse a junção das características de sua identificação precoce e demostrasse qual a origem. Os níveis altos podem se dar por outros motivos que acabam influenciando no exame como: gravidez, endometriose benigna, fibroses ou cistos ovariano, cirrose, hepatite, pancreatite e principalmente quando a paciente tem câncer de mama ou no colorretal (OLIVEIRA GG e FONSECA CA, 2011).

Os marcadores auxiliam nas investigações e rastreamento através do sinal de "alerta" que emite, indicando que mais exames serão fundamentais, por isso é utilizado na triagem, pode detecta o tumor na fase inicial. $O$ diagnóstico de câncer feito com a biopsia, utilizam os marcadores para predizer se haverá evolução do tumor, auxiliando na escolha do melhor tratamento. A monitorização do tratamento é feito para qualificar as respostas terapêuticas, é realizado em curto e regulares períodos de tempo para que tenha um acompanhamento efetivo. Detecção da reincidência de câncer é a importantíssima etapa do tratamento de verificar se há recorrência, pois quanto mais cedo é descoberto melhores são os prognósticos e mais eficaz será o tratamento (ARAÚJO JHG, 2013).

O câncer de ovário produz uma enzima chamada CA 125, é identificado através da quimioluminescência. Este exame é realizado com uma amostra sanguinea, onde se utiliza o soro para realizar a medição. $O$ resultado considerado normal seria abaixo de $35 \mathrm{U} / \mathrm{ml}$. Quando esse marcador se encotra elevado está associado ao câncer de ovário, podendo esta relacionado ao câncer de colo de útero, mama, cólon, fígado, pâncreas e pulmão. O CA 125 aumenta a sua expressão em aproximadamente $90 \%$ das mulheres com câncer em estágio avançado de ovário e em $40 \%$ dos pacientes com tumor intra-abdominal. A sensibilidade para 0 diagnostico é cerca de $80 \%$ a $85 \%$, variando entre as fases que se encontram o tumor, na fase inicial a sensibilidade é menor (Fase I - 50\%), e nas fases mais avançadas apresenta um aumento significativo (Fases: II - 90\%, III - 92\% e IV - 94\% (NAZARETH JJDO, et al., 2021),

O estadiamento caracteriza o câncer, como localização, propagação, e se influência nas funções orgânicas. Quando os cânceres de ovário que não está claramente dissipada são estadiados cirurgicamente, onde coleta-se amostra para caracterização através de analise laboratorial. Os estágios do câncer ovariano variam de I a IV. Os cânceres com estágios parecidos possuem um prognóstico similar e são tratados de forma parecida ou igual dependendo do caso (AMERICAN CANCER SOCIETY, 2018).

Os dois sistemas utilizados para o estadiamento é o sistema da Federação Internacional de Ginecologia e Obstetrícia (FIGO) e o sistema de TNM da American Joint Committee on Cancer (AJCC). Ambos usaram três critérios para avaliar: o tumor, os linfonodos regionais e ao redor e se o tumor se disseminou. A sigla TNM significa tumor $(\mathrm{T})$, linfonodo $(\mathrm{N})$ e metástase $(\mathrm{M})$, onde o $\mathrm{T}$ indica o tamanho e propagação do tumor primário (parede do ovário ou trompas de Falópio); $\mathrm{N}$ descreve a propagação para os linfonodos regionais ou se tem evidência de metástases em andamento; $M$ indica se tem metástase. Na tabela abaixo temos a organização dessas fases (Figura 2) (AMERICAN CANCER SOCIETY, 2018).

Figura 2 - Estadiamento do câncer de ovário.

\begin{tabular}{c|c}
\hline Estadiamento AJCC e FIGO & Estágios do câncer \\
\hline Estádio I & T1, N0, M0 \\
Estádio IA & T1a, N0, M0 \\
Estádio IB & T1b, N0, M0 \\
Estádio IC & T1c, N0, M0 \\
Estádio II & T2, N0, M0 \\
Estádio IIA & T2a, N0, M0 \\
Estádio IIB & T2b, N0, M0 \\
Estádio III A1 & T1 ou T2, N1, M0 \\
Estádio III A2 & T3a, N0 ou N1, M0 \\
Estádio III B & T3b, N0 ou N1, M0 \\
Estádio III C & T3c, N0 ou N1, M0 \\
Estádio IV A & Qualquer T, qualquer N, M1a \\
Estádio IV B & Qualquer T, qualquer N, M1b \\
\hline
\end{tabular}

Fonte: Pontes NS e Soares CP, 2021; dados extraídos de American Cancer Society, 2018. 
De acordo com a AJCC temos a seguintes classificação:

Estágio I: O tumor se restringe aos ovários, se subdivide em estágio la (câncer acomete apenas o interior de um ovário); estágio lb (acomete os dois ovários); estágio lc (Câncer no interior e superfície de um ou dois ovários, ou há células cancerígenas extraídas do líquido no abdômen durante cirurgia) (AMERICAN CANCER SOCIETY, 2018).

Estágio II: O câncer se dissemina para pélvis. Se divide em estágio lla (câncer acomete útero e/ou trompas de falópio); estágio llb (acomete outros tecidos da pélvis, como bexiga, uretra e reto); estágio Ilc (se disseminou para outros tecidos da pélvis e possui células cancerígenas no líquido extraído do abdômen) (AMERICAN CANCER SOCIETY, 2018).

Estágio III: Cancer acomete órgãos fora da pélvis, como revestimento e gânglios linfáticos do abdômen. Se subdivide em estágio IIIA (células cancerígenas visíveis pelo microscópio em amostra do revestimento abdominal, IIIA1: acomete somente linfonodos retroperitoneais; IIIA2: acometimento peritoneal extrapélvico, com ou sem agressão a cadeia linfonodal); estágio IIIB (células cancerígenas visíveis a olho nu no revestimento abdominal possuindo cerca de dois centímetros); estágio IIIC (células cancerígenas maiores que dois centímetros, encontradas no revestimento abdominal, e/ou gânglios linfáticos da barriga, virilha ou parte posterior do útero) (AMERICAN CANCER SOCIETY, 2018).

Estágio IV: tumor se alastrou para órgãos distantes do ponto de origem (ovário). Se divide em estágio IVA (contém células cancerígenas no líquido pleural); estágio IVB (câncer acomete a parte interna do fígado, baço, gânglios linfáticos, órgãos ou tecidos) (AMERICAN CANCER SOCIETY, 2018).

O CA 125 ou MUC 16 é uma sialomucina, faz parte da família glicoproteínas mucinas agrupada pelo gene MUC 16, conhecido desde os anos 80 . Foi identificado através de anticorpos coletados de animais imunizados com um tipo de célula cancerigena proveniente do ovário humano (cistodenocarcinoma seroso papilífero). Ocorre aumento dessa proteína no plasma quando se tem câncer de ovário, podendo se alterar no período menstrual e ovulação (BRASIL, 2012).

Quando a paciente está em período menstrual ou em alguma fase que libere normalmente o antígeno CA 125 no sangue, Brasil (2012) indica que nesses casos o valor deve serconsiderado normal de $65 \mathrm{a} 200 \mathrm{U} / \mathrm{ml}$, ou seja, apenas valores que ultrapassem essa margem devem ser considerados indícios de algo suspeito. Esse marcador está relacionado a doenças invasivas ou que possua uma extensa área de disseminação, especialmente ao câncer de ovário, onde os valores de referencias vão se encontrar mais elevados, e sofrem pouca influência quando o tumor e delimitado.

Mesmo com a realização de exames para diagnóstico, temos aproximadamente $20 \%$ de erro (falso negativo). A aplicabilidade dos indicadores CA 125 no manejo clinico, tem o intuito de identificação do cânceres de ovário, linfoma e até de outros tumores, principalmente no trato genital feminino. No pósoperatório é utilizado este marcador para nortear o prognóstico de sobrevida da paciente, assim surgindo alguns critérios que devem ser seguidos, tais como: Monitoramento dos primeiros três ciclos de quimioterapia, tendo como base a vida media do CA 125 na paciente; Possuir o valor do antígeno CA 125 antes do inicio do tratamento com a quimioterapia e depois quando estiver no seu segundo ciclo, para comparar se houve normalização ou diminuição dos valores do marcador, devendo estar entre 70 a $10 \mathrm{U} / \mathrm{ml}$; Consideram ser um prognóstico ruim quando os valores não diminuem com a realização das quimioterapias, nesses casos o CA 125 estão maiores que $20 \mathrm{U} / \mathrm{ml}$ (GADDUCCl A, et al., 2015).

A melhor forma de prevenção é o diagnóstico precoce, isso vale para todos os tipos de cânceres, somente a identificação prévia a intervenção será eficaz e rápida, em ralação aos encontrados em níveis avançado, levando a maior dificuldade em se obter um prognostico positivo, tendo em vista que o tratamento será mais prolongado e com altas doses de medicamentos, deixando o paciente com deficit imunológico por mais tempo, assim, abrindo porta de entrada para doenças oportunistas. No caso das pacientes com historio familiar de carcinoma ovariano, é indicado que faça uma ooforectomia preventiva (retirada de um ou dois ovários), sendo mais eficaz quando é realizado antes dos 35 anos. Alguns fatores auxiliam na prevenção dessa neoplasia como amamentação, utilização de contraceptivos orais, ligadura tubária e a gravidez precoce (25 á 30 anos) (MERCK SHARP E DOHME (MSD), 2019). 
Os marcadores vieram com a função de identificar o câncer de ovário em mulheres assintomáticas, presumindo-se que teria o poder de sinalizar o tumor em sua fase inicial, associado-o a ultra-sonografia, caso a massa ovariana for exarcebada, para confirmar hipótese e identificar risco de malignidade tumoral. É indicado que tenha regularidade nas realizações de check-up, principalmente se possuir histórico na família. O médico observara nos exames solicitados se os sistemas estão trabalhando corretamente. Em pacientes com diagnóstico de câncer ovariano é necessário que tenha um médico especialista na área, para que seja acompanhada de perto. Mesmo com a variedade de métodos diagnósticos, não possuímos uma triagem eficiente direcionada as mulheres assintomáticas, ou seja, não temos um exame de identificação $100 \%$ confiável (GADDUCCI A, et al., 2015).

Das terapêuticas que possuímos as mais eficazes contra os cânceres são cirurgicas, radioterapias, quimioterapias, sempre levando em consideração a idade do paciente, a recorrência, tipo do tumor, entre outros, e mesmo assim segundo Brasil (2012), após o paciente concluir o tratamento com a quimioterapia e com os valores normalizados de CA 125, ainda há presença de células doentes em $50 \%$ dos casos. Após a realização da cirurgia da retirada do tumor, é indicado a realização de sessões de radioterapias, para que destrua quaisquer resquício de células cancerígenas. Os índices de reincidência chegam a ser de $70 \%$ dos casos registrados, onde o CA 125 emitiu sinais, após três a cinco meses depois do termino da terapia, ou seja, ainda havia presença de fragmento tumoral, nesse caso é mais indicado que realize biopsia e exames de imagens para confirmar hipótese de retorno da doença, pra que se tome outras medidas mais agressiva em relação ao tratamento.

As causas que influenciam diretamente ou indiretamente nos fatores de risco são, a utilização de medicamentos (repositores hormonais, principalmente estrogênio), histórico familiar, ginecológico e nuliparidade. O câncer de origem familiar apresenta $5 \%$ dos eventos registrados, sendo necessário maior atenção, por possui uma característica hereditária forte. Quando se tem presença de tumores benignos ou malignos entre familiares, a probabilidade de surgir algum tumor é maior. Possui-se alguns fatores de risco ligado à recidiva dos pacientes (cerca de 60\% no Brasil), tais como, histologia mucinosa (células claras), histologia da célula com pouca diferenciação, surgimento de uma ascite durante a citorredução cirúrgica e mesmo utilizando o melhor tratamento quimioterápico existente os níveis séricos de CA 125 permanecerem altos (BRASIL, 2019).

Dependendo das características apresentados pelos tumores pode-se classifica-los como maligno ou benigno, de acordo com o tipo de células observados, crescimento, delimitações e se possui metástase ou não (Figura 3). O nível sérico de CA 125 são úteis para identificação e classificação, principalmente entre metástases, carcinoma seroso ou tumores primários malignos do ovário (MUKUDA N, et al., 2018).

Figura 3 - Tabela comparativa de tumor benigno e maligno.

\section{Tumor Benigno}

Compostos por células bem diferenciadas, com estruturas típicas do tecido de origem

Crescimento progressivo; pode regredir; mitoses normais e escassas

Massa bem delimitada, expansiva, não invade nem infiltra tecidos próximos

Não ocorre metástase

\section{Tumor Maligno}

Formado por células anaplásicas; atípicas; falta de diferenciação

Crescimento rápido; mitose anormais e numerosas

Massa pouco delimitada, localmente invasivo; infiltra tecidos adjacentes

Metástase normalmente presente

Fonte: Pontes NS e Soares CP, 2021; dados extraídos de Brasil, 2017.

O nível sérico do CA 125 acompanha o tamanho do tumor, expressado com mais evidência em canceres agressivos e/ou quando tomaram boa parte do órgão, em contrapartida quando o tumor é bem delimitado e/ou atinge o epitélio ovariano o nível sérico diminui significativamente. O CA 125 apesar de possui uma alta sensibilidade nos tumores mais severos, em relação as detecção das recidivas, não fez muita diferença no quesito de diminuir a morbidade ou mortalidade das pacientes que possuem o câncer ovarian (MUKUDA N, et al., 2018). 
Os biomarcadores séricos têm sido aplicados na prática clínica dos Estados Unidos baseadas nas diretrizes da academia nacional de bioquímica clínica, porém fundamentados nos estudos realizados chegaram conclusão que o CA 125 e vários outros marcadores não conseguem identificar os tumores em sua fase inicial, devido a baixa quantidade de produção dessas proteínas que servem como "alerta" (CHI PD, et al., 2014). Os exames que são normalmente solicitados para diagnósticos do carcinoma de ovário são ultra sonografia, tomografia computadorizada, ressonância magnética e os marcadores tumorais. Apesar de possuir uma grande sorte de tipos de exames, infelizmente ainda não são eficazes para a identificação precoce do tumor.

Stasenko M, et al. (2021), demonstram em seus estudos a utilização do CA 125 como marcador para a confirmação da diminuição do tamanho do câncer ovariano, diante de tratamentos experimentais, isso demonstra que ainda nos dias atuais se utilizar o biomarcador para rastreamento e acompanhamento do aumento ou baixar dos níveis séricos baseados nos valores apresentados pelo CA 125.

\section{CONSIDERAÇÕES FINAIS}

Dado o exposto, pode-se afirmar que os resultados confirmam a importância do marcador CA 125 na rotina de diagnóstico médico. Utilizado até os dias atuais na prática clinica, com o objetivo de detectar o câncer independente do tipo, já que o marcador se provou específico para doença cancerigenas. Mais estudo devem ser realizados para que o mesmo possa ser aplicado na prevenção além do diagnóstico,e desta forma capacitar e qualificar a equipe professional para melhor atendimento humanizado dos pacientes.

\section{REFERÊNCIAS}

1. AMERICAN CANCER SOCIETY. 2018. In: Ovarian Cancer Stages. America: Last Revised. Disponível em: https://www.cancer.org/cancer/ovarian-cancer/detection-diagnosis-staging/staging.html. Acesso em: 10 maio de 2021.

2. ARAÚJO JHG. Principais marcadores tumorais utilizados na prática clínica: uma revisão bibliográfica. Repositório Institucional da UFPB, 2013; 19-68.

3. BRASIL. Ministério da Saúde. 2012. Disponível em: http://conitec.gov.br/images/Incorporados/DosagemAntigenofinal.pdf. Acessado em: 19 de abril de 2020.

4. BRASIL. Ministério da Saúde. 2017.2 Disponível em:http://bvsms.saude.gov.br/bvs/saudelegis/sas/2017/prt0458_07_03_2017.html. Acessado em: 22 de agosto de 2020.

5. BRASIL

Ministério

da Saúde.

2019.

Disponível em:http://conitec.gov.br/images/Relatorios/2019/Relatorio_DDT_NeoplasiaMalignaEpitelialdeOvario_2019.pdf. Acessado em: 22 de agosto de 2020.

6. CHI PD, et al. High-density lipoprotein cholesterol is a favorable prognostic factor and negatively correlated with Creactive protein level in non-small cell lung carcinoma. Plos One, 2014; 9(3): e 91080.

7. GADDUCCI A, et al The predictive and prognostic value of serum CA 125 half-life during paclitaxel/ platinum-based chemotherapy in patients with advanced ovarian carcinoma. Anticancer Research, 2015; 35: 1099-1104.

8. INSTITUTO NACIONAL DE CÂNCER (INCA). Ministérios de Saúde. 2021. Disponível em:https://www.inca.gov.br/tipos-de-cancer/cancer-de-ovario. Acessado em: 17 de março de 2021.

9. MERCK SHARP E DOHME (MSD). Manual MSD. 2019. Disponível em: https://www.msdmanuals.com/pt$\mathrm{br} /$ profissional/ginecologia-e-obstetr\%C3\%ADcia/neoplasias-ginecológicas/câncer-ovariano. Acessado em: 10 maio de 2021.

10. MUKUDA N, et al. Bilateral Ovarian Tumors on MRI: How Should We Differentiate the Lesions?. Japan, Yonago Acta Medicica, 2018; 61: 110-116.

11. NAZARETH JJDO, et al. Biossensor: uma evolução biotecnológica no diagnóstico precoce do câncer. Brazilian Journal of Surgery and Clinical Research (BJSCR), 2021; 34 (1), 61-68.

12. OLIVEIRA GG, FONSECA CA. Uso de Marcadores Tumorais no Diagnósticoe Acompanhamento doTratamento do Cancer. Revista Eletrônica de Farmácia, 2011; 8 (2), 60-74.

13. STASENKO M, et al. Targeting galectin-3with a high-affinity antibodyfor inhibition of high-grade serousovarian cancer and other MUC16/CA-125-expressing malignancies. New York - USA: Scientific Reports, 2021; $11: 3718$

14. SZUBERT M, et al. CA-125 concentration in serun and peritoneal fluid in patients with endometriosis-preliminary results. Archives ofMedical Science. 2012; 8(3): 504-508.

15. ZOMER MT, et al. Correlação entre os níveis de Ca-125séricos e os achados cirúrgicos em mulheres com sintomas sugestivos deendometriose. Revista Brasileira de Ginecologia e Obstetrícia; 2013, 35(6):262-267. 